\title{
Virtual OSCE: Experience and challenges with a large cohort of pharmacy students
}

\author{
Hanis Hanum Zulkifly, Izzati Abdul Halim Zaki, Mahmathi Karuppannan, Zakiah Mohd Noordin \\ Department of Pharmacy Practice, Faculty of Pharmacy, Universiti Teknologi MARA Cawangan Selangor, Malaysia
}

\author{
Keywords \\ COVID-19 \\ Education \\ Pharmacy undergraduate \\ Virtual OSCE

\section{Correspondence} \\ Zakiah Mohd Noordin \\ Department of Pharmacy Practice \\ Faculty of Pharmacy \\ Universiti Teknologi \\ MARA Cawangan Selangor \\ Kampus Puncak Alam, 42300 \\ Bandar Puncak Alam, Selangor \\ Malaysia \\ zakiahmn@uitm.edu.my
}

\begin{abstract}
In response to the inability to conduct conventional face-to-face objective structured clinical examination (OSCE) due to the COVID-19 lockdown, this study explored options to design virtual OSCE (VOSCE) that meets the objectives and standards of effective competency-based assessment for a large cohort of pharmacy students. The vOSCE required advanced planning of the actual assessment and technical conduct. The development of a master plan consisting of the types of competencies to test, topics and number of cases, and assessment rubrics, guided the team members to develop an adequate OSCE assessment module. Technical aspects included recruitment of examiners, simulated patients (SP), technical support, and a platform for vOSCE. The main challenges were to ensure well-ordered vOSCE and a stable internet connection for examiners, SP, and students. Google Meet was utilised due to its functionality, familiarity, and low internet consumption to all parties involved. Feedback was obtained from stakeholders to improve future OSCE conduct.
\end{abstract}

\section{Introduction}

Globally, the ongoing COVID-19 pandemic has caused a significant toll in various sectors, including the education field. The lockdown regulation in Malaysia has forced most educational institutions to put off physical teaching, learning, and assessment activities and extended the virtual conduct. While the traditional teaching and learning activities have been successfully transformed into virtual media, the transformation process of the face-to-face clinical assessment modality known as Objective Structured Clinical Examination (OSCE) holds a different and more significant challenge to both educators and students (Ali, 2020; Alshammari, 2020).

OSCE is a clinical competence assessment where students need to complete a series of stations assigned with tasks of specified duration, encompassing one or multiple domains of learning. The evaluation of students' competency using a rubric or checklist highlights OSCE's objectivity and standardisation principles (Harden \& Gleeson, 1979). Due to its high reliability and validity, OSCE is considered the gold standard for competency-based assessment in clinical science courses, such as pharmacy, medicine, and nursing (Sturpe, 2010; Kristina \& Wijoyo, 2019). OSCE plays a fundamental role in the pharmacy curriculum, particularly in assessing the ability of students to perform practical, professional, and communication skills in preparation as future pharmacists. The adoption of real-life pharmacy practice scenarios in OSCE offers students the opportunity to demonstrate their interpersonal, problem-solving, psychomotor, and decision-making skills. It allows assessing students' performance not only based on what they learned from books but also through clinical application of the knowledge (Awaisu et al., 2010). The implementation of OSCE in pharmacy education is in tandem with the philosophy and practice of pharmaceutical care, where pharmacists have expanded their role and responsibilities in drug therapy management and patient care (McGivney et al., 2007). 
Several relevant factors must be considered in restructuring OSCE delivery via virtual mode. During the development of competencies to be tested, significant time is spent planning and ensuring that assessment endpoints are met and that the integrity of OSCE is highly protected. Therefore, discussion on simulated clinical scenarios in line with skills to be assessed, number of stations, development of virtual assessment rubric, and utilisation of digital security tools must be initiated early with all stakeholders (Hopwood et al., 2020; Updike et al., 2021). The practicality of the simulated scenarios and stations to be transformed online, for instance, converting the physical students' rotation between stations, must be designed in an easy-to-follow online OSCE circuit to minimise potential technical errors (Kakadia et al., 2020; Deville et al., 2021).

Furthermore, vOSCE requires the proper utilisation of qualified human resources and people experienced in handling technology tools, including the availability of Information Communication Technology (ICT) support and virtual platforms that best suits the examiners, students, simulated patients, and faculty staff (Tabatabai, 2020). Virtual platforms, such as Google Meet, Cisco Webex, Zoom, and Microsoft Teams, have been utilised by several educational institutions to conduct vOSCE (Elnaem et al., 2021; Hopwood et al., 2021; Savage et al., 2021). The selection of a virtual platform must consider institution or setting-specific factors. Breakout rooms and simplicity in displaying information, the familiarity of the stakeholders, and the internet data consumption are essential functionalities needed to support vOSCE's design. These aspects are critical and should be explored in advance, especially in large vOSCE cohorts, as they will affect assessment duration and human resource management.

All stakeholders must undergo training or rehearsal using the selected platform prior to the vOSCE day to ensure they are familiar with their role within the vOSCE and the logistics of how it will run. The training or rehearsal session using sample stations will highlight potential technical problems such as inability to access the virtual platform, delay in transitioning between stations, unclear case presentation on screen and nonfunctioning cameras or microphones. This session is also essential to boost stakeholders' confidence and ensure they are competent in using the platform during actual vOSCE (Lim et al., 2020; Hopwood et al., 2021).

OSCE has been an integral part of clinical competence assessment in the Universiti Teknologi MARA Bachelor of Pharmacy programme. The OSCE framework in this study follows the general guidelines where students are required to complete specific tasks at multiple standard stations within an allocated time frame. Each station varies in the competency tested and designed scenario complexity based on the course learning outcomes. This review will describe the authors' experiences and challenges while planning and implementing the virtual OSCE (vOSCE) for third and final-year undergraduate students.

\section{Course description and assessment methods}

For third-year students, the vOSCE was conducted under the Pharmaceutical Care course (PHC 505), a three-credit-hour compulsory course to be enrolled during the first term of the 2020-2021 academic session. The course curriculum consisted of 120 contact hours: 26 for didactic lectures, equivalent to 52 hours of student learning time (SLT), 12 for practical with equivalent hours of SLT, and the remaining contact hours were allocated for assessments consisting of tests, final exams, and OSCE. The key learning outcomes of the course include the integration of the pharmaceutical care concept, identification and resolution of drug-related problems, and application of the evidence-based approach in evaluating patient and pharmaceutical care information. The implementation of VOSCE in this course was in line with the aim to assess psychomotor, cognitive, and affective domains of learning outcomes.

For final-year students, the vOSCE was offered in two Clinical Pharmacy Courses: PHC 550 (Applied Therapeutics in Cardiovascular and Respiratory Disorder) and PHC 551 (Applied Therapeutics in Infectious Disease and Neoplastic Disorders). Both were core courses, equivalent to four credit hours with a total of 160 contact hours: 28 contact hours dedicated for didactic lecture (equivalent to 56 hours of SLT), four contact hours for problem-based learning (PBL) or eight hours of SLT, and the remaining hours allocated for tutorials, two tests, and one OSCE. Both courses served to provide the students with skills required to identify, prevent, and solve drug-related problems. The emphasis is placed on problem-solving, critical thinking, communication, patient counselling, drug information retrieval, and drug therapy monitoring. Students must integrate knowledge in pathophysiology, pharmacology, and pharmacotherapy into patient care. Case studies on therapeutic problems involving cardiovascular, respiratory systems, infectious disease, and neoplastic disorders were discussed during lectures and PBL. The main learning outcomes for both courses include the ability of students to i) assess systematically the primary medical and pharmaceutical care issue, ii) discuss the therapeutic outcome and recommend appropriate treatments available that provide the best pharmaceutical care, 
and iii) formulate strategies to solve problems, including providing alternative treatment procedures and preventive measures in cardiovascular, pulmonary, infectious disease, and neoplastic disorders.

\section{During COVID-19 virtual OSCE}

Restriction due to movement control order in Malaysia has impeded the conduct of conventional face-to-face OSCE. Thus, responsible committees at the faculty explored options to design virtual OSCE (vOSCE) that meets the objectives and standards of effective competency-based assessment. In this section, the authors share their experiences and challenges during the planning and conduct of vOSCE for third and final-year undergraduate pharmacy students.

\section{vOSCE experiences}

Development of the master plan
A vOSCE committee was created among the faculty members, which included the authors $\mathrm{HHZ}, \mathrm{ZMN}$, and IAHZ. The main tasks of this committee were to determine the competencies to be assessed, ensure that the format of the cases is in line with the pre-determined competencies, and discuss the technical conduct of the vOSCE.

Following an agreement from the department members on the competencies to be assessed, a three-station vOSCE consisting of two active stations and one preparatory station was designed for third-year students (Table I). Cases and rubrics for each station were designed by the teaching lecturers of pharmaceutical care courses. To reduce the possibility of students sharing case information, four cases that were randomised among the examiners were prepared for each station. Although the information such as patient demographics and types of medications prescribed were different between the cases, the core content, format, and level of difficulty were standardised.

Table I: Summary of OSCE stations for third-year students

\begin{tabular}{|c|c|c|c|c|c|c|}
\hline Stations & Competency tested & Blooms taxonomy & Task & $\begin{array}{c}\text { Time } \\
\text { (minutes) }\end{array}$ & Evaluator & $\begin{array}{l}\text { Type of } \\
\text { session }\end{array}$ \\
\hline Station 0 & None & None & $\begin{array}{l}\text { Self-introduction (Name } \\
\text { and student } \\
\text { identification) }\end{array}$ & 0.5 & None & $\begin{array}{l}\text { Non- } \\
\text { interactive }\end{array}$ \\
\hline Station 1 & $\begin{array}{l}\text { Screen prescription and } \\
\text { identify related legislative } \\
\text { and prescribing errors } \\
\text { Identify drug-related } \\
\text { problem and design } \\
\text { appropriate } \\
\text { pharmaceutical care plan } \\
\text { to address the identified } \\
\text { problem }\end{array}$ & $\begin{array}{l}\text { Cognitive } \\
\text { Retrieve learned } \\
\text { information and evaluate } \\
\text { errors in prescription and } \\
\text { identify potential drug } \\
\text { related problem }\end{array}$ & $\begin{array}{l}\text { Students were given a } \\
\text { short scenario and a } \\
\text { prescription to be } \\
\text { screened. Student was } \\
\text { allowed to use standard } \\
\text { references and is } \\
\text { required to verbally } \\
\text { provide answer to the } \\
\text { examiner at the station. }\end{array}$ & 5 & Examiner & $\begin{array}{l}\text { Non- } \\
\text { interactive }\end{array}$ \\
\hline Station 2 & $\begin{array}{l}\text { Develop professional } \\
\text { relationship with patient } \\
\text { Communicate drug-related } \\
\text { information in effective } \\
\text { manner } \\
\text { Demonstrate correct } \\
\text { technique of using medical } \\
\text { device }\end{array}$ & $\begin{array}{l}\text { Affective } \\
\text { Receive, respond, value, } \\
\text { internalise, and act upon } \\
\text { presented stimuli } \\
\text { (patient's video clip). } \\
\text { Psychomotor } \\
\text { Use of motor skills and } \\
\text { actions by demonstrating } \\
\text { the correct technique of } \\
\text { using medical device. }\end{array}$ & $\begin{array}{l}\text { Students were } \\
\text { presented with } 1 \text { minute } \\
\text { video clip of a patient } \\
\text { showing how he usually } \\
\text { use his medical device. } \\
\text { From this clip, students } \\
\text { were required to } \\
\text { identify any errors from } \\
\text { patient's technique and } \\
\text { provide counselling to } \\
\text { correct the identified } \\
\text { errors. }\end{array}$ & $\begin{array}{l}7 \\
\text { (Including } \\
1 \text { minute } \\
\text { patient's } \\
\text { video clip) }\end{array}$ & Examiner & Interactive \\
\hline
\end{tabular}

Next, vetting of the cases and rubrics was conducted at three levels. The first level involved the vetting process among the teaching team, who evaluated whether the cases and rubrics were in line with the competencies assessed, content relevancy, standard level of difficulty, vocabulary, and grammatical errors. Upon completion of the L1 vetting, cases and rubrics were sent for level two (L2) vetting by three principal lecturers who were experts in vOSCE. Cases and rubrics were updated following comments and suggestions agreed during the $L 1$ and $L 2$ vetting process. The third level of vetting involved the final check and endorsement by the head of department (MK). The endorsed cases and rubrics were uploaded in the virtual vOSCE Google Drive using password protected files. 
Four faculty members developed a master plan for final-year students, consisting of the competencies assessed, the methods and stations involved. This master plan served as a guideline for all teaching teams for the preparation of cases. It includes a template of the case, stations involved, tasks for the students in each station, timings, SP script, assessment rubrics, and marks for each station.

Competencies and cases were developed based on the course learning outcomes and Bloom's taxonomy for both PHC 550 and PHC 551, respectively (Table II). Five cases were developed for each subject to minimise the chances of students sharing case information as they were not quarantined as per the conventional face-toface OSCE session. Students were also randomised for assessment to only one case during the actual vOSCE day. Cases for the PHC 550 course covered the therapeutic area of myocardial infarction, hypertension, asthma, chronic obstructive pulmonary disease, and cystic fibrosis. For PHC 551 course, cases included the therapeutics of pneumonia, human immunodeficiency virus, urinary tract infection, syphilis, and lung cancer. The format of the cases and rubrics were standardised among both subjects (Table II). Vetting of the cases and rubrics were conducted similarly to third-year cases mentioned above.

Table II: Summary of OSCE stations for final-year students

\begin{tabular}{|c|c|c|c|c|c|c|}
\hline Stations & Competency tested & Blooms taxonomy & Task & $\begin{array}{c}\text { Time } \\
\text { (minutes) }\end{array}$ & Evaluator & $\begin{array}{l}\text { Type of } \\
\text { session }\end{array}$ \\
\hline Station 1 & None & $\begin{array}{l}\text { Cognitive } \\
\text { Ability to remember and } \\
\text { understand the case synopsis }\end{array}$ & $\begin{array}{l}\text { Self-introduction } \\
\text { (Name and student } \\
\text { identification). } \\
\text { Students were asked to } \\
\text { read the case synopsis }\end{array}$ & 2.5 & None & $\begin{array}{l}\text { Non } \\
\text { interactive }\end{array}$ \\
\hline Station 2 & $\begin{array}{l}\text { Develop professional } \\
\text { relationship, obtain } \\
\text { information and } \\
\text { establish effective } \\
\text { communication skills } \\
\text { with patients }\end{array}$ & $\begin{array}{l}\text { Psychomotor } \\
\text { Use of motor skills by jotting } \\
\text { down patient's history of } \\
\text { medical illness, medication, } \\
\text { social history and current } \\
\text { problem. } \\
\text { Affective } \\
\text { Receive, respond, empathise } \\
\text { and value the patient's medical } \\
\text { history }\end{array}$ & History taking & 5 & Examiner & $\begin{array}{l}\text { Interactive } \\
\text { with } \\
\text { simulated } \\
\text { patient }\end{array}$ \\
\hline Station 3 & $\begin{array}{l}\text { Identifies and provides } \\
\text { recommendations to } \\
\text { resolve drug related } \\
\text { problems }\end{array}$ & $\begin{array}{l}\text { Cognitive } \\
\text { Relate, analyse and apply } \\
\text { information obtained in station } \\
1 \text { and } 2 \text { to identify potential } \\
\text { drug related problems. } \\
\text { Justify and recommend } \\
\text { effective solutions to the drug } \\
\text { related problems identified. }\end{array}$ & $\begin{array}{l}\text { Identify drug related } \\
\text { problems, justify and } \\
\text { recommend effective } \\
\text { solutions. Student was } \\
\text { allowed to use } \\
\text { standard references } \\
\text { such as British National } \\
\text { Formulary (BNF), Drug } \\
\text { Information Handbook. }\end{array}$ & 5 & Examiner & $\begin{array}{l}\text { Interactive } \\
\text { with } \\
\text { examiner }\end{array}$ \\
\hline Station 4 & $\begin{array}{l}\text { Develop professional } \\
\text { relationship, obtain } \\
\text { information and } \\
\text { establish effective } \\
\text { communication skills } \\
\text { with patient. }\end{array}$ & $\begin{array}{l}\text { Affective } \\
\text { Receive, respond, empathise } \\
\text { and value patient's discharge } \\
\text { prescription. } \\
\text { Cognitive } \\
\text { Provide appropriate discharge } \\
\text { counselling and monitoring } \\
\text { parameters upon discharge }\end{array}$ & $\begin{array}{l}\text { Discharge counselling } \\
\text { and monitoring } \\
\text { parameters }\end{array}$ & 5 & Examiner & $\begin{array}{l}\text { Interactive } \\
\text { with } \\
\text { simulated } \\
\text { patient }\end{array}$ \\
\hline
\end{tabular}

\section{Students grouping}

A total of 183 third-year students and 185 final-year students were involved in the vOSCE. For the third-year students, the vOSCE session was held on 7 January 2021, while final-year students had two sessions held on 14 and 15 January 2021 for the subjects of PHC 550 and PHC 551, respectively. A similar grouping method was utilised for all three vOSCE sessions, except that third-year students were not assigned with simulated patients. The students were divided into 20 groups of about nine to ten students each. These groups were assigned to one examiner (lecturer) and a simulated patient (SP). The student list was available in the vOSCE instruction manual provided to students a week before. The list consisted of their names, e-mail addresses, contact number, and the allocated time slot for each student. Students were asked to check their particulars to ensure they were correct before the vOSCE day. They were required to sign and submit an academic integrity form a week prior to the vOSCE. This initiative ensured 
that the integrity of the examination was well protected.

\section{Examiners' recruitment}

A total of 20 lecturers from the Faculty of Pharmacy were appointed from the academic team of the Faculty of Pharmacy as vOSCE examiners of third and fourthyear students. Then, the examiners were briefed on their roles, vOSCE cases, and the evaluation system. A day before the vOSCE, examiners' packs, which contained the vOSCE manual, materials for each station (password protected files), student list name, and links for Google Meet and Google Form (rubric), were emailed to each examiner. A WhatsApp group was also created between the technical team and the examiners to facilitate communication and ensure prompt response during the vOSCE day. Google Meet was the medium used to conduct vOSCE. Each examiner was instructed to have their own examination room with their sets of students. They were asked to create their own Google Meet link one week before the actual day of vOSCE. Their Google Meet link was compiled in one Google Sheet and this master sheet (Figure 1) was shared among all examiners and the technical team to monitor any problem experienced by the examiner, students and SP during the session that the technical team can rectify and solve.

\begin{tabular}{|c|c|c|c|c|c|c|c|c|}
\hline & A & в & c & D & E & $\mathrm{F}$ & $\cdots$ & . \\
\hline \multicolumn{9}{|l|}{1} \\
\hline 2 & $\begin{array}{c}\text { Examiner } \\
\text { No. } \\
\end{array}$ & Google Meet Name & Examiner & \begin{tabular}{|l} 
Simulated patient \\
\end{tabular} & Contact no & Google Meet Link & Google Form Link (551) & Case \\
\hline 3 & 1 & [T1] Exam Room 1 & Prof ABD & Mr $A B C$ & $010-x x x x$ & hitps://meet.google.com/rss-uanr-kwk & https://forms.gle/TCDTXnsAS2WuLA7v8 & \\
\hline 4 & 2 & [T1] Exam Room 2 & & & & meet.google.com/fzi-xeag-avp & hittps://forms.gle/gZeHKipNANKy5ipg9 & \\
\hline 5 & 3 & [T1] Exam Room 3 & & & & https://meet.google.com/tan-cyan-bma & https://forms.gle/5C2Uyz5wYZ1wNAsVA & \\
\hline 6 & 4 & [ए1] Exam Room 4 & & & & hittps://meet.google.com/boe-cbra-ibv & https://forms.gle/mRiEu2DFuFMah6ri7 & \\
\hline 7 & 5 & [T1] Exam Room 5 & & & & hittps://meet.google.com/pua-kciz-ecy & hittps://forms.gle/NJWX1KAexB8DyGSV8 & \\
\hline 8 & 6 & [T1] Exam Room 6 & & & & hittps://meet.google.com/ogw-zpxo-rxp & hittps://forms.gle/QQ6R6Kh2eF28m1567 & \\
\hline 9 & 7 & [T1] Exam Room 7 & & & & https://meet.google.com/kpu-aaag-pyh & hitps://forms.gle/bMtJNNKYu1ZHPPUJVZ6 & \\
\hline 10 & 8 & [T1] Exam Room 8 & & & & https://meet.google.com/hcq-behv-iif & https://forms.gle/7ZwDezn59x68gSVSA & \\
\hline 11 & 9 & [T1]Exam Room 9 & & & & hittps: $/ /$ meet.google.com/mzf-zcre-xoz & hittps://forms.gle/ufGt17snNUjiksZpQ7 & \\
\hline 12 & 10 & [T1] Exam Room 10 & & & & http://meet.google.com/mpe-wwwn-abs & \multirow{2}{*}{ https://forms.gle//Z67azTGicTmrUoM7 } & \\
\hline 13 & & & & & & & & \\
\hline 14 & 11 & [Т2] Exam Room 1 & & & & https://meet.google.com/ovx-ouaf-xma & hittps://forms.gle/zVNrAE9gsdggKmB98 & \\
\hline 15 & 12 & [T2] Exam Room 2 & & & & https://meet.google.com/mer-ycnh-qrz & hittps:/fforms.gle/xYEWV8GDphw7s6VHA & \\
\hline 16 & 13 & [Т2] Exam Room 3 & & & & https://meet.google.com/eur-ufha-zib & https://forms.gle/DSe44Hiz6iT5ziGw8 & \\
\hline 17 & 14 & [П2] Exam Room 4 & & & & https://meet.google.com/iyp-emgp-uhu & https://forms.gle/SvgCi4bCoRWKQX5a6 & \\
\hline 18 & 15 & [Т2] Exam Room 5 & & & & https://meet.google.com/ywn-tcrh-ynn & hitps://forms.gle/YUwpzcBbwh3BJyQx5 & \\
\hline 19 & 16 & [12] Exam Room 6 & & & & https://meet.google.com/vix-fpgy-apx & hittps://forms.gle/hdvdrYZstFdKYZEL.7 & \\
\hline 20 & 17 & [12] Exam Room 7 & & & & https://meet.google.com/wki-amuy-bxa & hittps://forms.gle/8edW86uknWeV6ax98 & \\
\hline 21 & 18 & [Т2] Exam Room 8 & & & & https://meet.google.com/fix-huxz-ywa & https:/fforms.gle/wkr5gUd2iCMKiaby5 & \\
\hline 22 & 19 & [Т2] Exam Room 9a & & & & https:l/meet.google.com/gth-kzje-xkd & hittps:/fforms.gle/QoV86iks3pViw61W8 & \\
\hline 23 & 20 & [Т2] Exam Room 10 & & & & https://meet.google.com/ffe-bbrd-abg & hittps://forms.gle/hdvdrYZstFdKYZEL.7 & \\
\hline 24 & & & & & & & & \\
\hline & & & $\begin{array}{l}\text { Name of ex } \\
\text { contact nun } \\
\text { difficulties }\end{array}$ & $\begin{array}{l}\text { s, SPs and their } \\
\text { case of technical }\end{array}$ & & $\begin{array}{l}\text { gle meet link for all exam rooms } \\
\text { ilable in case of technical } \\
\text { iculties }\end{array}$ & $\begin{array}{l}\text { Google form link for all examiners } \\
\text { available to ease marking }\end{array}$ & \\
\hline
\end{tabular}

Figure 1: Master sheet containing all information on Google Meet links, Google Form links, name of examiners and contact numbers of SPs and clinical case

\section{Simulated patients (SP) recruitment}

Simulated patients were not physically involved in third-year students vOSCE. However, at station two, the students were presented with a one-minute video of a patient showing the patient's techniques of using a medical device. The video clip was pre-recorded with an actor using an actual medical device. Due to the limited time to recruit real SPs, examiners at the station played both the role of evaluators and patients during the corrective counselling at this station. Although the device counselling station is generally considered difficult to be transformed into vOSCE due to the absence of physical devices for both the students and examiners, the use of a medical device video has provided students with a unique telehealth experience. Given the increasing need for telehealth during the
COVID-19 pandemic, vOSCE can be adopted as an excellent strategy and opportunity to teach and assess pharmacy students' ability to provide pharmaceutical care remotely.

Twenty SPs were involved in the final year vOSCE. They were alumni of the Faculty of Pharmacy who volunteered to be involved in the vOSCE sessions. They were briefed on their role and were trained to understand the script three days before the actual session. A password-protected script for each case was prepared and disclosed to the SPs the night before the actual vOSCE session. A WhatsApp group was created between the technical team and SPs to facilitate communication before, during, and after the session. SPs were asked to sign an integrity agreement so as not to leak the script to their fellow juniors. 


\section{Students preparation}

A virtual briefing was done with both cohorts of students at least twice before the vOSCE session to disseminate information regarding the dates, flow, the platform to be used, and expectations. A mock video of the VOSCE was played to enhance their overall understanding of the whole process. They were also reminded to find a stable internet connection on the day of vOSCE to ensure smooth sailing of the whole process. Any questions raised by the students were answered during this recorded briefing session, which was later made available on Google Classroom for easy access to the students.

\section{Flow of the actual vOSCE}

In deciding the flow of vOSCE, various meetings, consultations, and discussions were undertaken between the academic staff at the faculty and external academic staff from other local universities offering a Pharmacy Degree programme to ensure that the flow is consistent with other educational institutions using OSCE as an assessment method for pharmacy courses in Malaysia.
The flow of VOSCE for the third-year students involved three stations consisting of one preparatory and two active stations, as seen in Figure 2 . The vOSCE was conducted over a restricted date and time frame to reduce the risk and opportunity for students to share information. On the day of VOSCE, students were invited to join their respective Google Meet session according to their scheduled timing. Upon joining the Google Meet session, students were instructed to introduce their names and identification number at Station 0. Next, at station one, students were given a short case scenario and a prescription to screen. They were allowed to use standard references and were given five minutes to provide their answer verbally to the examiner at the station. Subsequently, at station two, after watching the one-minute patient's video, students were required to identify any errors from the patient's technique and provide corrective counselling on the identified errors. A total of seven minutes duration was allocated for this station, including the one-minute patient's video clip. Upon completing the two stations within the allocated time, students were allowed to leave the Google Meet session. Examiners were then required to submit students marks via the prepared Google Form.

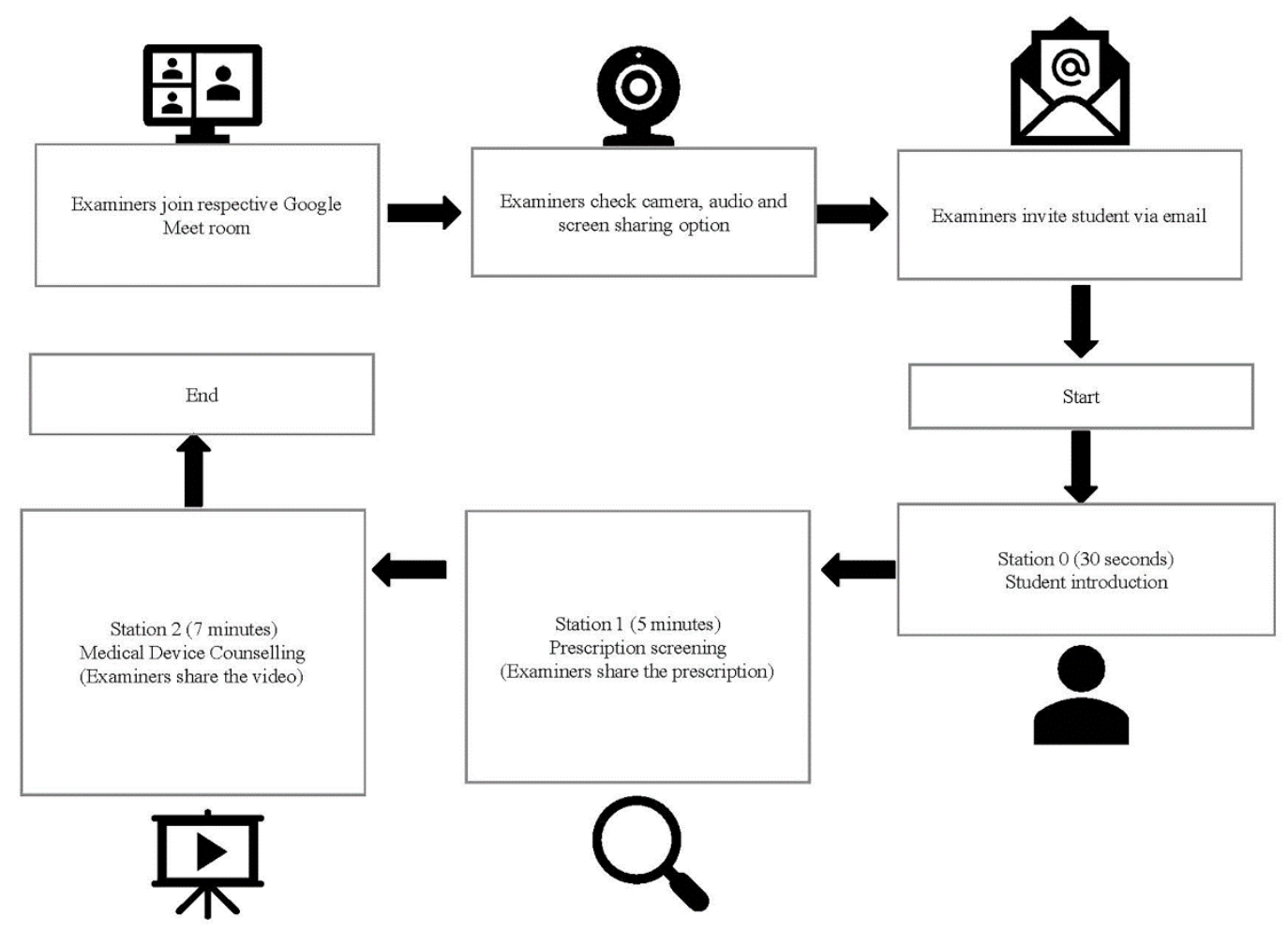

Figure 2: Flow of vOSCE for third-year students

The flow of vOSCE for final-year students involved four stations, as seen in Figure 3. Lecturers and SPs were instructed to join their respective Google Meet 45 minutes prior to the actual time for the camera, audio, and other technical issues to be checked and sorted. A total of 20 Google Meet sessions occurred concurrently and were monitored by the technical team members. Examiners were asked to invite their first student based 
on the name list provided five minutes before the actual session. Once the first student was in and comfortable, the timer started for the first station. In this station, students introduced themselves for 30 seconds and had two minutes to read the case synopsis. This station was followed by stations two, three, and four, consisting of history taking, identifying, and solving drug-related problems and performing discharge counselling, respectively, for five minutes each. The timing for each station was handled solely by the examiners.

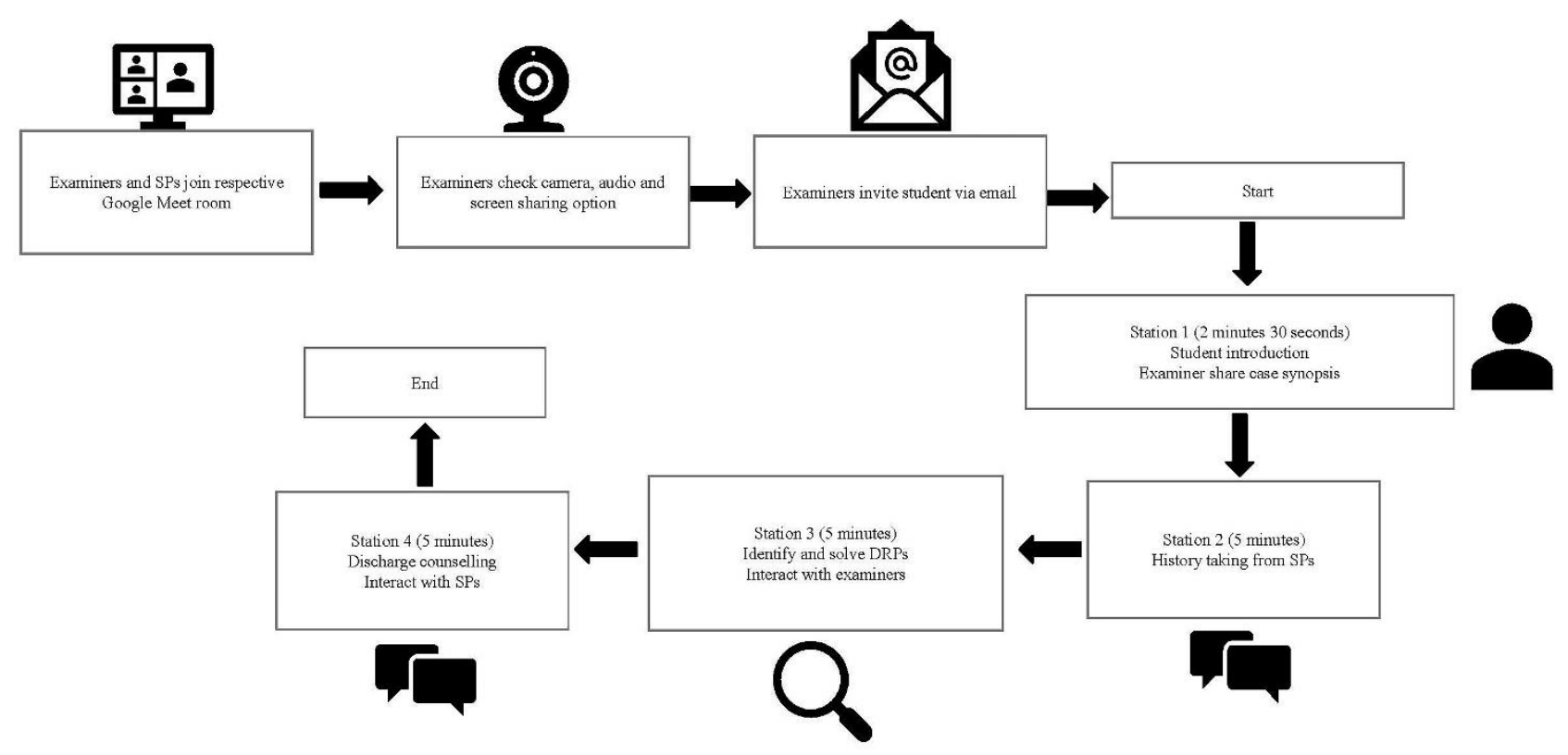

Figure 3: Flow of vOSCE for fourth year students

The examiners shared all documents pertaining to stations one to four via the "share-screen" function on Google Meet. Once students completed all four stations, they were asked to leave the Google Meet session, and the examiners continued this process for all 9-10 students assigned to them. The examiners were required to assess students on the spot and put their marks on the Google Form created earlier. If there was any technical difficulty on either side, students and the lecturers were asked to communicate with the technical team for help. All examination rooms were recorded, and the recordings were kept by the vOSCE coordinators if remarking was required.

\section{Evaluation}

For third and final-year students vOSCE, the evaluation was performed using assessment rubrics comprising objectively designed marking scheme. The rubrics were vetted to ensure the developed marking scheme was concise, focused, and unambiguous to allow clear discrimination of good performances from the poor ones. The scoring system also took into consideration all possible performances and allowed the provision of scores according to the level of the student's achievements. The rubrics were then transformed into a virtual assessment platform using Google Form (Figure 4). A briefing session on the rubrics was conducted among the examiners to ensure a standardised evaluation system.

\section{Feedback}

Both third and final-year students were given a questionnaire after the vOSCE session for feedback purposes. The questionnaire for the third-year students consisted of their satisfaction with the Google Meet medium used, the logical sequence of the stations, and their agreement with the task, time, and instructions given. The majority of students agreed that Google Meet was suitable, the station sequence was logical, tasks reflected teaching contents, and instructions were clear. However, only half of the students agreed that time was sufficient for both stations. Some students mentioned that the video played in station two was not smooth; hence, it impacted their ability to identify errors from the patient's technique. 


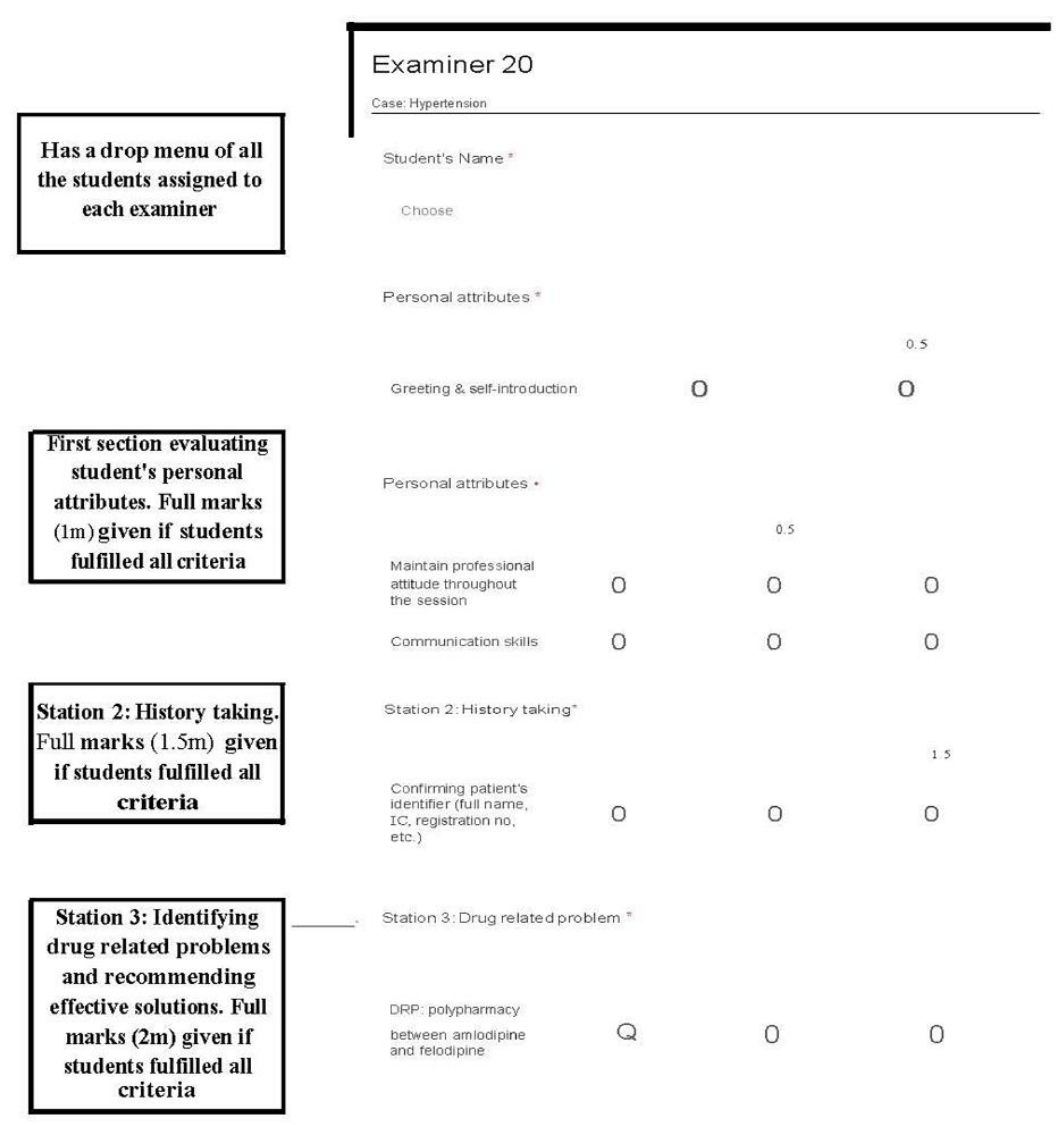

Figure 4: Example of rubrics transformed to Google Form

A questionnaire sought the opinion and satisfaction of final-year students with the medium, design, organisation, knowledge covered, and instructions prior to vOSCE. The majority were satisfied with the use of Google Meet as a platform for OSCE, agreed that the vOSCE was designed fairly, organised adequately, and covered a wide range of knowledge. Information and instructions were clear as responded by many students. More than half agreed that the task at each station was interesting and educative, and the presence of SPs was helpful at stations two and four. Nonetheless, only half agreed that vOSCE was a valuable experience and an accurate measure of essential clinical skills. Besides, the majority felt that the time given at each station was insufficient. Only a minority of students were not satisfied with the examiners they received and were afraid that this might impact their results. However, they were satisfied with their new experience with vOSCE that helped them think critically in a short period and enhanced their communication skill with the SP.

Apart from that, SPs and examiners were also asked about their experience and opinion on the assessment and conduct of vOSCE. Most examiners agreed that tasks reflected components of assessment, time allocation was sufficient, and instructions were clear. Despite that, a minority felt that the assessment rubrics lacked detailed counselling marks. Simulated patients thought that the session was well conducted; it was a new experience for them, and they felt that students were able to apply their history-taking skills by asking them the correct questions. However, some had a poor internet connection, which affected their session. But extra time was given for those who experienced poor internet connection.

\section{Challenges}

Mechanism

Planning for the OSCE to be conducted virtually was way more complex than the conventional OSCE. In designing the flow of vOSCE, the most critical factor to consider was the stability of the internet connection for both examiners and students. Time was very crucial while running the OSCE. Any disruption to the flow would affect the whole OSCE session. Hence, to minimise the possibility of interruption, the authors utilised the Google Meet function by Google Suites for Business subscribed by the institution, which uses a 
minimal amount of data and is stable in areas with moderate to a poor internet connection. The low data consumption through Google Meet was advantageous compared to other online meeting platforms (Mulyani et al., 2021). Students typically moved from one station to another in the conventional OSCE compared to staying in one meeting room for all the stations. This method of OSCE saved time and ensured the smooth flow of OSCE for the day.

During the conventional OSCE, students were quarantined in one dedicated room to ensure that they were not communicating after the OSCE. However, due to the limitation in VOSCE, it was not practical to develop a virtual quarantine room, which would require students to stay online for almost five hours and consume a large amount of data. Hence, a slight modification was made to the grouping of students for each examiner. As a result, each examiner was assigned an average of nine students per group for the entire vOSCE compared to the conventional OSCE, where one examiner was assigned 13 to 14 students.

\section{Human resources}

The examiners for vOSCE were selected among the lecturers who were registered pharmacists in Malaysia. It was also crucial to ensure that the examiners had a stable internet connection. The different geographical locations where examiners may reside might affect internet connection stability during the examination. With the sudden pandemic that shifted to online learning, challenges arose among examiners who are not tech-savvy. A study among 180 academicians in Malaysia found that $45.5 \%$ of respondents did not have a suitable workplace at home, where 92 respondents had data plans below $40 \mathrm{~GB}$ despite the majority having internet data connection at home (Ahmad Tajuddin et al., 2021). Intensive training sessions were conducted for the examiners to help them familiarise themselves with the platform and mechanism of the virtual OSCE. SPs played a vital part in OSCE, as errors are more likely to occur when examiners are required to shift tasks between the examiner and SP or prescriber, either when OSCE is conducted conventionally or virtually (Wong et al., 2021). Therefore, in designing the vOSCE, it was also essential to recruit the SP who could commit to online training and was available on the day of the vOSCE.

\section{Designing cases and tasks}

Designing OSCE cases and tasks for the virtual OSCE was more challenging than the conventional OSCE. All the possible factors must be considered, including the examiners and students. The cases designed for vOSCE were short and concise as internet stability was the biggest challenge. However, the shorter amount of time allocated for each station during vOSCE compared to the conventional OSCE may not allow assessing student ability and skills comprehensively, as reported by a recent study (Lim et al., 2020)

\section{Conclusion}

The pandemic has forced the transformation of a faceto-face to a virtual OSCE assessment without compromising its quality. This process was possible despite the large number of students involved, thanks to advanced planning, dedicated team, and cooperation of key stakeholders. Feedback gathered from stakeholders will be used to improve future OSCE.

\section{Acknowledgement:}

The authors are truly indebted to examiners from the Department of Pharmacy Practice and other departments in the Faculty of Pharmacy, Universiti Teknologi MARA, simulated patients, and everyone for their contribution and support in running this virtual OSCE. The authors are also thankful for all feedback and suggestions from the faculty staff, students, and simulated patients on the implementation of this virtual OSCE.

\section{Authorship}

$H H Z, I A H Z$, and $Z M N$ wrote and edited the manuscript. MK reviewed and edited the manuscript and all authors have seen and approved the final manuscript for publication.

\section{Conflict of interest}

All authors do not have any conflict of interest.

\section{Ethics statement}

Not required.

\section{References}

Ahmad Tajuddin, A. J., Romly, R., Hamzah, Y., Wan Hussin, W. M. R., \& Muda, W. (2021). Lecturers' Readiness and Emotional Presence on Online Teaching Data in a Malaysian 
University During COVID-19.

https://doi.org/10.2991/assehr.k.210312.088

Ali, M. (2020). What now and what next? The new era of OSCE. Pharmacy Education, 20, 56-58. https://doi.org/10.46542/pe.2020.202.5658

Alshammari, E. (2020). Implementing eOSCE During COVID19 Lockdown. Journal of Advanced Pharmacy Education And Research, 10(1), 174-180. Available at: https://japer.in/en/article/implementing-eosce-duringcovid-19-lockdown

Awaisu, A., Abd Rahman, N. S., Nik Mohamed, M. H., Bux Rahman Bux, S. H., \& Mohamed Nazar, N. I. (2010). Malaysian pharmacy students' assessment of an objective structured clinical examination (OSCE). American journal of pharmaceutical education, 74(2), 34-34. https://doi.org/10.5688/aj740234

Deville, R. L., Fellers, C. M., \& Howard, M. L. (2021). Lessons learned pivoting to a virtual OSCE: Pharmacy faculty and student perspectives. Currents in Pharmacy Teaching and Learning. https://doi.org/10.1016/j.cptl.2021.06.046

Elnaem, M. H., Akkawi, M. E., Nazar, N. I. M., Ab Rahman, N. S., \& Mohamed, M. H. N. (2021). Malaysian pharmacy students' perspectives on the virtual objective structured clinical examination during the coronavirus disease 2019 pandemic. Journal of educational evaluation for health professions, 18, 6-6.

https://doi.org/10.3352/jeehp.2021.18.6

Harden, R. M., \& Gleeson, F. A. (1979). Assessment of clinical competence using an objective structured clinical examination (OSCE). Medical Education, 13(1), 39-54. https://doi.org/10.1111/j.1365-2923.1979.tb00918.x

Hopwood, J., Myers, G., \& Sturrock, A. (2021). Twelve tips for conducting a virtual OSCE. Medical teacher, 43(6), 633 636. https://doi.org/10.1080/0142159X.2020.1830961

Kakadia, R., Chen, E., \& Ohyama, H. (2020). Implementing an online OSCE during the COVID-19 pandemic. Journal of dental education. https://doi.org/10.1002/jdd.12323

Kristina, S., \& Wijoyo, Y. (2019). Assessment of Pharmacy Students' Clinical Skills using Objective Structured Clinical Examination (OSCE): A Literature Review. Systematic Reviews in Pharmacy, 10, 55-60.

https://doi.org/10.5530/srp.2019.1.9

Lim, A. S., Lee, S. W. H., Karunaratne, N., \& Caliph, S. (2020). Pharmacy Students' Perceptions and Performance on the Use of an Online Virtual Experience Tool for Practicing Objective Structured Clinical Examinations. American journal of pharmaceutical education, 84(11), 7920. https://doi.org/10.5688/ajpe7920

McGivney, M. S., Meyer, S. M., Duncan-Hewitt, W., Hall, D. L., Goode, J. V., \& Smith, R. B. (2007). Medication therapy management: its relationship to patient counseling, disease management, and pharmaceutical care. J Am Pharm Assoc, 47(5), 620-628. https://doi.org/10.1331/JAPhA.2007.06129

Mulyani, M., Fidyati, F., Suryani, S., \& Halimatussakdiah, H. (2021). University students' perceptions through e-learning implementation during COVID-19 pandemic: Positive or negative features dominate? Studies in English Language and Education, 8, 197-211.

https://doi.org/10.24815/siele.v8i1.17628

Savage, A., Minshew, L. M., Anksorus, H. N., \& McLaughlin, J. E. (2021). Remote OSCE Experience: What First Year Pharmacy Students Liked, Learned, and Suggested for Future Implementations. Pharmacy (Basel), 9(1). https://doi.org/10.3390/pharmacy9010062

Sturpe, D. A. (2010). Objective structured clinical examinations in doctor of pharmacy programs in the United States. American journal of pharmaceutical education, 74(8), 148-148. https://doi.org/10.5688/aj7408148

Tabatabai, S. (2020). Simulations and Virtual Learning Supporting Clinical Education During the COVID 19 Pandemic. Advances in medical education and practice, 11, 513-516. https://doi.org/10.2147/AMEP.S257750

Updike, W. H., Cowart, K., Woodyard, J. L., Serag-Bolos, E., Taylor, J. R., \& Curtis, S. D. (2021). Protecting the Integrity of the Virtual Objective Structured Clinical Examination. American journal of pharmaceutical education, 8438. https://doi.org/10.5688/ajpe8438

Wong, P. S., Tumkur, A., Shanmugham, S., Chong, D., Ingle, P., \& Ahmed, S. I. (2021). Implementing remote pharmacy objective structured clinical examination during the COVID19 pandemic. Pharmacy Education, 221-225. https://doi.org/10.46542/pe.2020.202.221225 